\title{
Book Review: Spaces of Contention: Spatialities and Social Movements
}

\author{
Blog Admin
}

As social movements have become more complex, geographers are increasingly studying the spatial dynamics of collective resistance, and sociologists and political scientists are increasingly analysing the role of space, place and scale in contentious political activity. Occupying a position at the intersection of these disciplinary developments, this book aims to examine how social movements have employed spatial practices to respond to and shape changing social and political contexts. Reviewed by Jenny Walklate.

\section{Spaces of Contention: Spatialities and Social Movements. Walter} Nicholls, Byron Miller, and Justin Beaumont (eds.). Ashgate. July 2013.

\section{Find this book:}

Immanuel Kant once wrote that space was a 'form of sensibility', an abstract medium through which humans perceive the world and, as such, a form of understanding. Space has long been a powerful presence in philosophy and critical theory; Lefebvre and Bachelard just two twentieth century exemplars. It seems strange then, that the idea of space as a politically productive entity is now arising as a 'new' notion in certain areas of academic discourse.

Yet this idea forms the basis for Spaces of Contention. Over three sections, twelve articles aim to present a 'state of the art analysis of how space plays a constitutive role in social movement mobilization.' In this review, I will briefly analyse a couple of the papers to showcase both

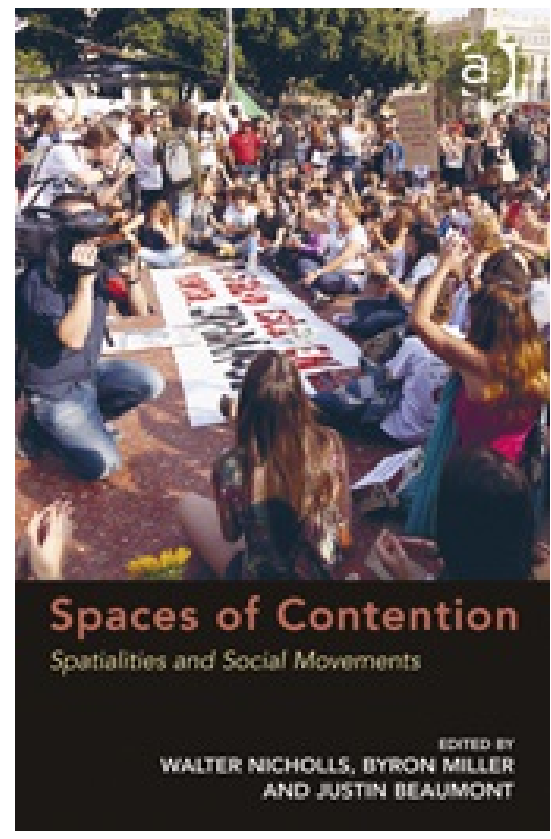
the positive and negative features of the book, before giving some more general comments.

Written by two political and social scientists and a PhD student, Chapter 1, 'Putting Protest in Place: Contested and Liberated Spaces in Three Campaigns' considers three Italian protest campaigns: No TAV, No Bridge, and No Dal Molin. The No TAV campaign, which began to emerge in the 1990s and continues to this day, protests against the construction of a 57 kilometre tunnel as part of a High Speed Rail Line (Treno Alta Velocita - TAV). No Bridge opposes the construction of a bridge across the Messina Straits proposed by the Berlusconi government, and has also been in operation since the late 1990s. No Dal Molin, a younger mobilization beginning officially in 2006 protests the expansion of US military bases near the city of Vicenza. No TAV in particular has been newsworthy, for in 2005 there was violence between protesters and police. This chapter provides a clear introduction to the idea of space as socially important and socially constructed, and conducts a good literature review regarding the spatial dimensions of social protests and movements. One particularly fascinating concept in this article is that protest itself doesn't just use space, but produces it too, both locally and globally.

However, the main body of the paper, detailing the three protests, is problematic. The case studies are crammed together, and there is a lack of structural clarity. The No Bridge campaign - a lengthy mobilization against a planned bridge over the Messina Straits - is particularly lost amidst the swell of the other two. No explicit methodology is described and the choice of case studies is never fully justified. This curtails the value of the paper, for anyone reading it cannot make a fully informed critical judgement about its reliability and worth. 
John Agnew is continually cited in this book, and with Ulrich Oslender wrote Chapter 6, 'Overlapping Territorialities Sovereignty in Dispute: Empirical Lessons from Latin America'. This echoes the previous chapter, by beginning with a strong history of the Westphalian model of state sovereignty: the dominance of nation-states over their geographic territory. There is also a vital and hitherto absent discussion of the different kinds of territory, suggesting that this is not merely the spatial organization of a state, but broader and more abstract. This is particularly powerful in regards to the compelling central discussion of the conflict in Bolivia, a country politically fragmented and fraught with tensions between the elected government, the wealthy European elites, and their often exploited workers. Perhaps the most subtle piece of analysis in this paper - and in this book - appears in the conclusion. Movements may rebel against official state territories, the authors argue, but in the process they can strengthen and legitimate the power and sovereignty of these authorities. This is perhaps the star paper of the volume.

There are things to admire about this collection. Its editors seem politically astute, and they revivify the rather antiquated basic conceit by focussing on contemporary events and concerns. They make extensive reference to preceding scholars in geography, sociology and political science, and present many nuanced concepts regarding spatial politics - 'terrains of resistance', 'structural hole' and 'broker/tertius' included. Most of these are well defined, though there is an occasional lack of clarity and relevance, such as occurs with Moyersoen and Swyngedouw's use of the term 'glocal' (p.144). Often, this is a very structurally clever book, with chapters linked in a chain by a variety of shared conceits; the Westphalian model links the paper of Jones and Agnew, and Mayer's paper is connected to that of Moyersoen and Swyngedouw through its focus on social actors. But image quality is poor, the figures inside entirely black and white. Figure 7.1 is rendered almost entirely indistinct and in Figure 6.1, it is impossible to tell the difference between 'Indigenous Reserves' and 'Lands of Black Communities'.

The conclusion is lengthy and returns to the content of each of the papers. Yet it does little more than repeat what each article has said, providing limited critical reflection. Neither does it present a synthesising final statement exploring whether the volume achieves its stated aim. At best, it is a condensed and uncritical literature review, not an analytical conclusion. This lack of analysis is endemic: few authors state their ideological, disciplinary and methodological frameworks, let alone analytically evaluate them.

Without a clear synthesising final statement it is difficult to say whether Spaces of Contention achieves its stated aim. This is not as ground-breaking a volume as perhaps its editors hoped, and no single paper lifts it to something more than the sum of its parts. A pity, for this could have been a highly charged and highly contentious political book, with something to say about academic practice. Instead it is a list of case studies, varying in quality. One might find a use for individual papers for a topic in which they are particularly interested, but there is no sustained cohesion to the book as a whole. For more theoretical and differentiated work on contention and resistance, works that Spaces of Contention itself cites might be of more use: Pile and Keith's Geographies of Resistance, or any number of papers from Environment and Planning D: Society and Space. For those interested in space itself, there might be more to gain from the work of John Urry on complexity theory and mobility, the now classic works of de Certeau and Lef ebvre, of course, or Soja's Postmodern Geographies and Thirdspace. Each of the monographs has more cohesion and ideological visibility than this very mixed collection. In every possible way, Spaces of Contention is just too safe.

Jenny Walklate recently completed a PhD in Museum Studies at the University of Leicester. Her research project used literary theory and strategies to investigate the production and experience of temporality in museum spaces. Read more reviews by Jenny. 